\title{
Managing the IE (Industrial Engineering) Mindset: A quantitative investigation of Toyota's practical thinking shared among employees
}

\author{
Phillip Marksberry, David Parsley \\ University of Kentucky (USA) \\ marksberry@,mfg.uky.edu;parsley@,mfg.uky.edu
}

Received December 2010

Accepted November 2011

\section{Abstract.}

Purpose: The goal of this work was to investigate the managerial practices of today to understand if Toyota is sheltering themselves from these newer practices or embracing them like most believe.

Design/methodology/approach: This work utilizes a new form of data mining named Latent Semantic Analysis (LSA) to analyze an organizations ideal management practices.

Findings: This work shows quantitatively that TPS favors earlier versions of industrial engineering compared to the optimization techniques available today.

Originality/value: The use of data mining to analyze organizational management practices.

Keywords: Toyota Production System (TPS), industrial engineering, lean manufacturing, dimensional reduction algorithms, management 


\section{Introduction}

Toyota's management system, more formally known as the Toyota Production System (TPS) is a modern technology aimed at reducing cost and eliminating waste. TPS, which is more commonly known as lean manufacturing, initially originated on the production floor, where several tools such as 5S, visual control and standardized work were created. Over the last decade, lean has grown from a manufacturing philosophy to a business strategy. Currently, companies all over the world are in a state of kaizen to modernize their accounting systems, design practices, maintenance areas and human resource functions to emulate their business systems like Toyota. While few researchers see gain in holding interest on a particular aspect of TPS, most consultants and authors actively seek new ways to apply lean in uncharted areas of the business. This craze to upload lean into all aspects of the business has weakened organizations mainly because practitioners insist on applying the manufacturing tools of lean (i.e. visual control, 5S, standardized work) rather than applying the thinking of lean.

What is unique about Toyota's system is not particularly any single piece of TPS, but how the pieces are combined to bring out something new, different and very difficult to imitate. So much work has been completed in examining and dissecting the parts of the Toyota Production System that little has been done to examine how the parts work together! It is argued in this work that Toyota's management system is a richly interconnected set of parts and relationships that are more important than the nature of the parts themselves. This means that even if the parts themselves can be identified, their relations are often lost, which loses meaning of the system. It is believed that research in TPS must follow the same type of systems thinking to discover how TPS emerges from the way the parts are organized in the system. Holism, rather than reductionism can provide a more entire solution than a partial one.

Historically, practitioners have been concerned about what Toyota is doing now rather than what was Toyota doing when TPS did not exist. Pioneers like Taiichi Ohno, the father of TPS and one of his close friends, Sheigo Shingo, an industrial engineering consultant to Toyota during the time, are less received and noted for developing TPS. In very simple terms, not to make TPS any more complicated than what it needs to be, TPS is an old way of thinking. In Ohno's book (Ohno, 1988), named the Toyota Production System, Ohno firmly believed that TPS is simply a form of industrial engineering (IE) aimed at reducing cost through systematic study. By treating everything as a process, Ohno and Shingo built the 
interconnections of TPS one by one, but more importantly passed on this industrial engineering way of thinking to future generations.

The purpose of this work is to evaluate and quantify some of Toyota's thinking styles as it relates to Ohno's traditional view of TPS. It is speculated that one of the ways Toyota is able to develop such a holistic approach to TPS is by passing down from generation to generation a type of thinking similar to industrial engineering. Managers throughout Toyota are believed to teach, share and develop this kaizen mind to encourage systematic study and evaluation of business practices. The secondary goal of this work is apply a new form of management science, named dimensional reduction analysis to highlight and quantify managerial preferences. This work is expected to substantiate quantitatively many of Toyota's perceived industrial engineering practices, but also indicate the particular form. Meaning, most outsiders view lean as an extremely sophisticated form of industrial engineering mainly due to the influences of six sigma, lean sigma and now the popularized kaizen specialist. Due to these latest trends, one could dispute that the flavor of industrial engineering is very different from Ohno's more practical view of productivity improvement. This work is expected to bring insight and hopefully simplicity into understanding an old familiar way of thinking about problems from an industrial engineering viewpoint that acts as a catalyst for making the TPS system come alive. In this work the link will between TPS and IE will be established and analyzed to determine which trend of IE practices are utilized to maintain the TPS structure.

\section{Literature review}

On August 15, 1945 Kiichiro Toyoda, then president of Toyota Motor Company, said: "Catch up with America in three years. Otherwise, the automobile industry of Japan will not survive" (Ohno, 1988). In Ohno's book Taiichi went on to say: "To accomplish this mission, we had to know America and learn American ways" (Ohno, 1988).

Ohno believed that the quickest way to catch up with America was to import American production management techniques and business management practices. Toyota studied industrial engineering (IE) which by Ohno's accounts can best be compared to the Toyota Production System. That is, a company-wide system tied directly to management to systematically lower cost and raise productivity. (Ohno, 1988). 
Shingo also viewed TPS as a way of thinking to addresses plant improvement. He believed that management should possess a set of fundamentals closely related to industrial engineering as a way to spread and teach the Toyota Production System.

Shingo believed that TPS is a system made up of principles that can be applied through practical implementation. If management cannot understand how to attack the rationalization of the current system, through scientific study, then it cannot be expected to improve or change. (Shingo, 2005).

\subsection{Industrial engineering}

An industrial engineer is one who is concerned with the design, installation and improvement of integrated systems of people, material, information and equipment which utilizes specialized knowledge and skills in mathematical, physical and social sciences together with the principles and methods of engineering analysis (Salvendy, 2001). Over the years industrial engineering has drawn upon mechanical engineering, economics, labor psychology, philosophy, and accountancy in an effort to bring together people, machines, materials and information (Saunders, 1982). If industrial engineers had to focus on one aspect of their field it would be productivity or productivity improvement. That is, the total elimination of waste by increasing efficiency through cost reduction (Going, 1911).

Industrial engineering not only covers the technical aspects of systems, but also systems relating to management. Anderson proposes that industrial engineering is one the primary drivers for linking the needs of the employers to the needs of the employees. Employers want industrial peace, reduction of cost, higher efficiency and improvement in quality. Employees want steady work, higher wages, better personal relations with their supervisor and good working conditions. By utilizing industrial engineering techniques, management can develop, evaluate and improve the wants of both groups (Anderson, 1928).

\subsection{Scientific management}

One of the earliest contributions to the field of industrial engineering and to the industrial efficiency movement in the early 1900s was by Frederick Taylor with his invention of scientific management (Taylor, 1911). Scientific management is the saving of energy, materials and time, or in other words the elimination of waste through studying, recoding and analyzing work. The Gilbreths (Frank and Lillian) also were advocates of scientific management and were concerned with how to properly raise productivity without degradation of an employee's health and well- 
being (Gilbreth, 1973). Scientific management was never a manner of how much a person can do under a short burst of speed but instead a safe and comfortable working speed that can be done day after day (Mogensen, 1935). Unfortunately, many charlatans attempting to break into the field of scientific study who had neither proper training nor interest except for the quick financial benefit portrayed scientific management incorrectly. Scientific management was intended to secure the maximum prosperity for the employer coupled with the maximum prosperity for the employee. The long term prosperity of the employer cannot exist unless it is accompanied by the prosperity of the employee (Gilbreth, 1973). Scientific management included employees to some degree in decision making. In 1935 Mogensen suggests that IEs (then referred to as efficiency experts) should solicit suggestions and ideas from those working directly with the operation. While it is assumed that workmen and foreman are incapable of such suggestions, some of the most valuable ideas have come from this source (Mogensen, 1935).

\subsection{Skill sets of industrial engineers in the era of scientific management}

Table 1 illustrates some of the basic efficiency tools and concepts used by industrial engineering during the era of scientific management. IEs were mostly concerned with defining processes, identifying problems and establishing standard operations (Harrington, 1911). Some of the most practical techniques employed by IEs was the use of direct observation and work sampling (Staley \& Delloff, 1963). Combined with a questioning attitude, IEs could obtain facts to make productivity improvements simply and quickly. The industrial engineer also was proficient with the use of charting. By breaking down processes into smaller units, the IE could analyze work flow by examining process steps visually.

Lastly, the IE was concerned with running trials to test new productivity ideas. By testing factors one at a time and by sequentially changing those parameters based on previous trials, the IE could speed up decision making while focusing on improvement. 


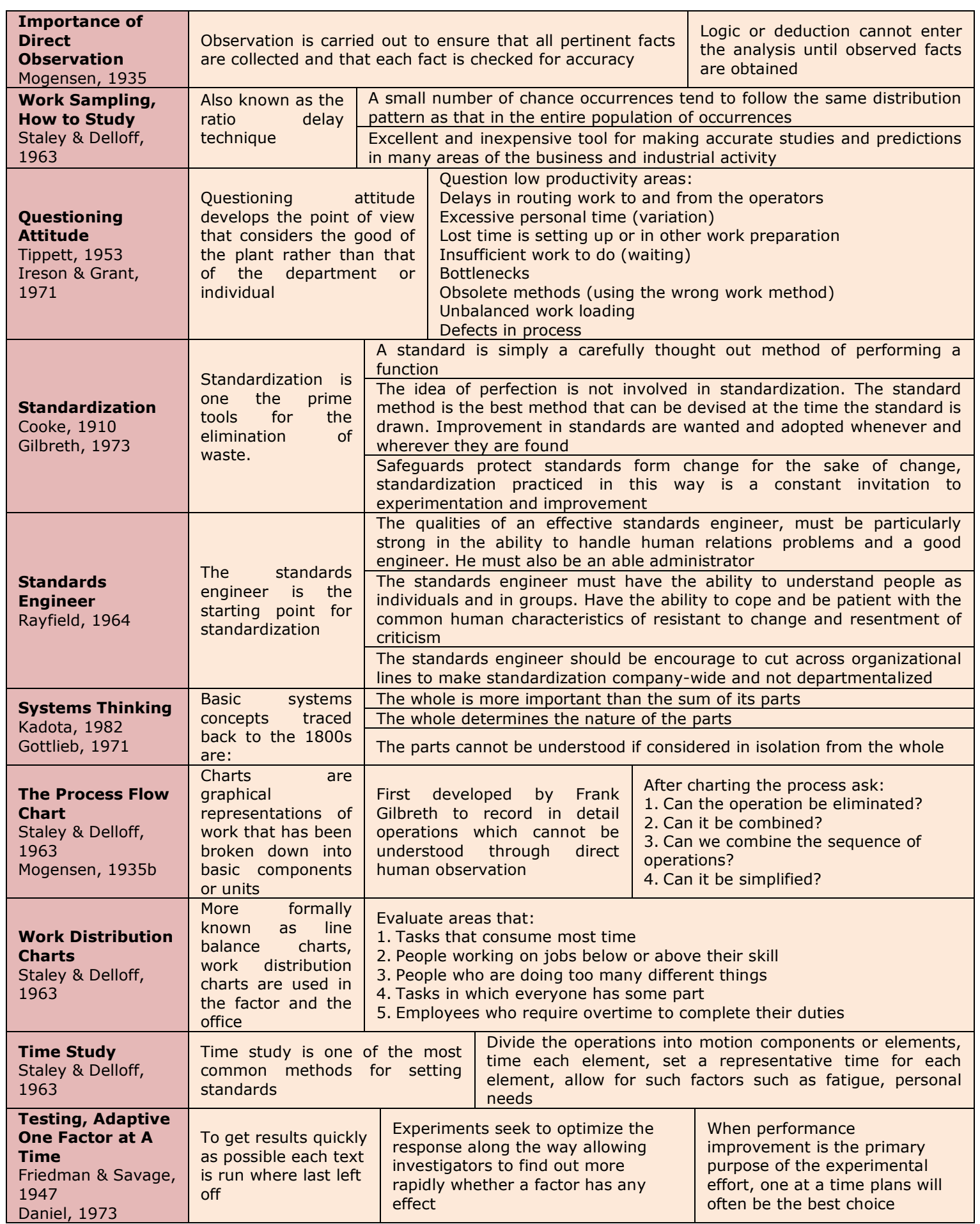

Table 1. Skill sets of industrial engineers in the era of scientific management

\subsection{Industrial engineering today}

Today, industrial engineering has become a more integral part of the organization. With the invention of the high speed computer in the 1960s industrial engineering has evolved into a hard discipline where data can be recalled at any time and decision making can be improved through the use of models and simulations 
(Saunders, 1982). Computers have given industrial engineers the ability to analyze and optimize complex systems throughout the organization (Katzell et al., 1977). The field has also become more specialized over the years much like mechanical engineering in the earlier twentieth century. Industrial engineering offers several sub specialties such as human factors, job design, labor psychology and systems engineering. Now it is not uncommon for IEs to work on planning systems, supply chains, accounting systems and organizational polices.

One of the most significant changes in the industrial engineering profession has been their role in change management (Zandin, 2001). One of the main reasons why the IE function has become more of a driver for change is the growth of service functions within modern industry. Because IEs are skilled to analyze socialtechnical systems they can help improve the fit between technology and the worker (Salvendy, 2001).

\subsection{Skill sets of industrial engineers in the 21st century}

The skill sets of the modern industrial engineer are much different compared to the days of scientific management. Most modern IE skill sets emphasize rapid organizational change instead of spending time stabilizing and documenting current operations. Techniques such as Process Design and Re-engineering can result in radical change by focusing on end to end processes. PDR assumes a clean state change and suggests skipping documenting existing processes because it limits the vision of the design team with nothing to be gained (Taylor et al., 2001).

A popular tool to aid in the study of complex organizational factors in PDR is Experimental Designs (ED) and Design of Experiments (DOE) concepts. These techniques allow industrial engineers to understand the complexities of the business and interacting factors acting on and within the organization before leaping towards a new state (Czitrom, 1999). Today DOEs are packaged with structured initiatives for business improvement known as Six Sigma and Lean Sigma (Pyzdek \& Keller, 2009; Wedgwood, 2007). Six Sigma is a systematic method for strategic process improvement that relies on statistical methods to make dramatic reduction in customer defect rates (Tanco et al., 2009). Initially established by Motorola in 1987, Six Sigma has been extremely popularized as new form of business management strategy (Jugulum \& Samuel, 2008). Six sigma often involves large masses of data and concerns itself with percentages and averages or the presentation of data in tables and charts (Bowker \& Lieberman, 1971). 
Lean Sigma is another improvement methodology that is being employed by industrial engineers. Proponents suggest that by integrating statistical methods with the ideas of work simplification a common language can be developed to help organizations be responsive to changing markets while eliminating defects (Wedgwood, 2007). Jugulum and Samuel suggest that the key to Lean Sigma is through integration. Six Sigma provides the detailed statistical study to optimize projects while lean is usually implemented through a series of short focused kaizen blitz. (Jugulum \& Samuel, 2008).

\begin{tabular}{|c|c|c|c|c|}
\hline $\begin{array}{l}\text { Systems } \\
\text { Engineering and } \\
\text { Optimization } \\
\text { Mar, } 1994 \\
\text { Ludwig, } 1968 \\
\text { Martens \& Allen, } \\
1969 \\
\text { Warfield, } 1994 \\
\text { Castro et al., } 2010 \\
\end{array}$ & \multicolumn{2}{|c|}{$\begin{array}{l}\text { Systems engineering divides the total } \\
\text { system into smaller subsystems, } \\
\text { specifies the input-output } \\
\text { requirements of each subsystem and } \\
\text { each smaller component and } \\
\text { determines the method of } \\
\text { interconnection in order to accomplish } \\
\text { the overall objective of the system }\end{array}$} & \multicolumn{2}{|c|}{$\begin{array}{l}\text { Systems are described mathematically } \\
\text { by their properties such as continuous, } \\
\text { discrete, lumped or distributed, linear } \\
\text { or non-linear, constant or time } \\
\text { varying, deterministic or structures } \\
\text { and behaviors }\end{array}$} \\
\hline $\begin{array}{l}\text { Process Design } \\
\text { and Reengineering } \\
\text { Taylor et al., } 2001 \\
\text { Lee \& Dale, } 1998 \\
\text { GAO, } 1995 \\
\text { Manganelli \& Klein, } \\
1994 \\
\text { Lee, } 1996\end{array}$ & \multicolumn{2}{|c|}{$\begin{array}{l}\text { A systematic discipline for achieving } \\
\text { dramatic, measurable performance } \\
\text { improvements by fundamentally } \\
\text { reexamining, rethinking and } \\
\text { redesigning the processes that an } \\
\text { organization uses to carry out its } \\
\text { mission }\end{array}$} & \multicolumn{2}{|c|}{$\begin{array}{l}\text { Reengineering processes are usually } \\
\text { described in terms of the beginning } \\
\text { and the end states, forces thoughts } \\
\text { towards the activities taking place } \\
\text { between the end points }\end{array}$} \\
\hline $\begin{array}{l}\text { Experimental } \\
\text { Design, Design of } \\
\text { Experiments, } \\
\text { Taguchi Methods } \\
\text { Anderson \& McLean, } \\
1974 \\
\text { Tanco et al., } 2009 \\
\text { Montgomery, } 2005 \\
\end{array}$ & $\begin{array}{l}\text { Experimental design } \\
\text { enables industrial } \\
\text { engineers to study the } \\
\text { effects of several } \\
\text { variables affecting the } \\
\text { response or output of a } \\
\text { process using statistics }\end{array}$ & $\begin{array}{l}\text { Taguchi's ap } \\
\text { DOE is b } \\
\text { orthogonal c } \\
\text { simplify and } \\
\text { testing }\end{array}$ & $\begin{array}{l}\text { proach to } \\
\text { oased on } \\
\text { designs to } \\
\text { accelerate }\end{array}$ & $\begin{array}{l}\text { Replications and } \\
\text { randomization is required } \\
\text { for an estimate of error to } \\
\text { determine the basis for } \\
\text { decision making on the } \\
\text { importance of factors } \\
\text { contributing to the } \\
\text { response variables }\end{array}$ \\
\hline $\begin{array}{l}\text { Six Sigm } \\
\text { Tanco et } \\
\text { Pyzdek \& } \\
2009\end{array}$ & $\begin{array}{l}\text { IEs specializing in } \\
\text { statistical improvement } \\
\text { utilizing quality } \\
\text { management processes } \\
\text { such as: }\end{array}$ & \multicolumn{3}{|c|}{$\begin{array}{l}\text { 1. Affinity diagrams } \\
\text { 2. Multivariate charts } \\
\text { 3. FMEA (failure mode and effects analysis) } \\
\text { 4. DMAIC (define, measure, analyze, improve, } \\
\text { control) } \\
\text { 5. Analysis of variance, ANOVA } \\
\text { 6. Regression analysis } \\
\text { 7. TRIZ }\end{array}$} \\
\hline $\begin{array}{l}\text { Lean Sigma } \\
\text { Wedgwood, } 2007 \\
\text { Jugulum \& Samuel, } \\
2008\end{array}$ & $\begin{array}{l}\text { A business improvement } \\
\text { strategy based on } \\
\text { combining the statistical } \\
\text { tools of Six Sigma and } \\
\text { the waste reduction } \\
\text { methodologies of lean }\end{array}$ & \multicolumn{3}{|c|}{$\begin{array}{l}\text { Integrating the tools of six sigma and lean include: } \\
\text { 1. Chi-square analysis and } 5 \mathrm{~S} \\
\text { 2. DOE and kanban } \\
\text { 3. FMEA and value stream mapping }\end{array}$} \\
\hline
\end{tabular}

Table 2. Skill sets of industrial engineers in the 21st century

\subsection{Has lean followed the trends of industrial engineering?}

The lean community has followed many of the same trends and skill sets as applied by the industrial engineering profession. While initially focused on more practical concepts in the days of scientific management, experts working in lean are now expected to lead transformational change utilizing advance statistical tools and techniques. 
The kaizen specialist is one of the main figure heads used by organizations in implementing lean (Liker, 2008; Dennis, 2007). Similar to the master black belts in Six Sigma, kaizen specialists are charged with developing solutions that aim to lower cost and improve efficiency of operations.

Bicheno suggests that a kaizen specialist should be capable of performing value engineering in product design and development (Bicheno, 2000). Other work indicates that specialist should be capable of performing environmental scanning using complex engineering techniques such as the $\mathrm{x}$-matrix, Porter's matrix and other sophisticated diagnostic tools (Jackson, 2006). Lastly, there is work that suggest the kaizen specialist should be able to perform cellular manufacturing, production flow analysis and supply chain infrastructure design (Askin \& Goldberg, 2002; Srinivasan, 2004). In these contexts, the kaizen specialist is illustrated as person that exists within an organization to advance lean concepts in highly specialized areas single handedly.

In other ways the kaizen specialist is also expected to work with employees utilizing team-based worker participation activities often referred to as kaizen events. Compared to extreme Taylorism, where the IE function is responsible for telling workers what to do, kaizen specialist appear to be much nicer and softer. For example, the work of Martin and Osterling state that these specialists should be armed with PowerPoint kick-off material, masking tape, whiteboards, post-it notes and kaizen team t-shirts (Martin \& Osterling, 2007). A successful kaizen event is one where the specialist can get employees to get involved and feel they have ownership (Tapping, 2007). While workers are more involved compared to extreme Taylorism, the kaizen specialist is still responsible for the results and outcome. Kaizen events are popular because they have been used to accelerate productivity improvements in a short amount of time (Mika, 2006).

\subsection{Is Toyota sheltered from modern industrial engineering?}

Figure 1 summarizes some of general skill set trends associated with industrial engineering and lean manufacturing. This conceptual illustration details the ongoing trends of specialization of the industrial engineering profession. IE handbooks today are emphasizing system optimization, advance computational mathematics and rapid overhaul within organizations. Interestingly, Toyota's approach to TPS appears to be highly shielded from modern trends in the industrial engineering profession and mainstream business improvement methodologies. In 1935 Sakichi Toyoda the founder of Toyota developed five basic teachings based on the Toyoda family work ethic. His teachings emphasized the importance of practicality, good 
study habits and healthy homelike work environment. In the 1950s Taiichi Ohno initiated a new type of production system (i.e. TPS) with an emphasis on standardization, just-in-time, jidoka and kaizen (Ohno, 1988). Ohno's shop floor focus and the idea of testing practical ideas immediately encouraged learning by getting employees to confirm failure with their own eyes (Ohno, 1988b). Ohno viewed that management should join with subordinates in experimentation and each supervisor must have the ability to teach. In 2001 Toyota continued this practical view of TPS when Fuijo Cho then President of Toyota Motor Corporation released the Toyota Way, a set of managerial values to strengthen the organizational thinking as it relates to work (Cho, 2001). The Way was based on five principles one being genchi genbutsu which in Japanese means "go and see for yourself." Toyota's constant reinforcing of getting managers out of the office and on to the shop floor to see for themselves appears to be a reoccurring trend within Toyota. In 2005 Cho re-issued the company's 8-step problem solving process named Toyota Business Practice (TBP) as an effort to share a common way of thinking about problems in the workplace (Cho, 2005). Again, Toyota's emphasis to attract and recruit employees to follow one system, one voice, one image of TPS is a much different trend compared to most other mainstream business improvement methodologies where one individual is expected to accomplish the needs of the organization single handedly.

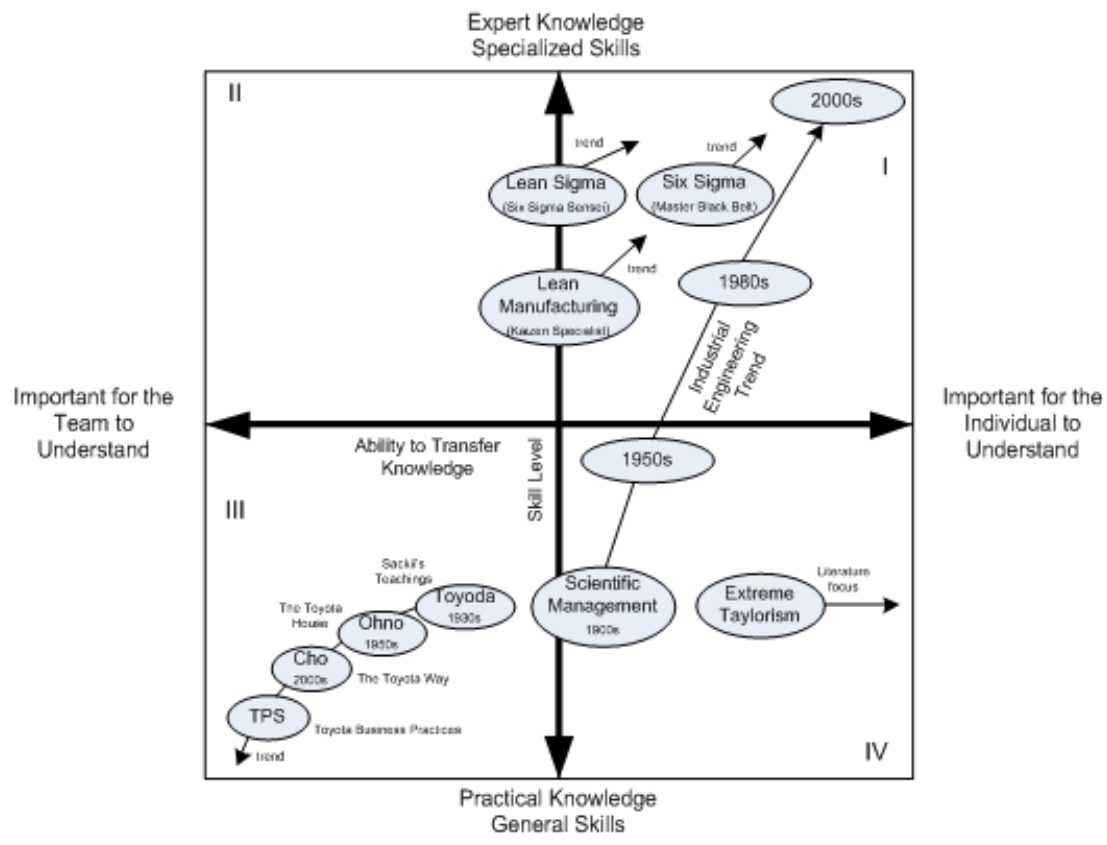

Figure 1. Representation of skills and business strategy influences for the IE profession 


\section{Research approach}

The overall approach in this analysis is to analyze Toyota's organizational documents by applying statistical data mining. This work will use Latent Semantic Analysis (LSA) to study Toyota's industrial engineering techniques, systems and managerial practices. LSA is a theory and method for extracting and representing the contextual-usage and meaning of words and phrases by statistical computation applied to text (Landauer, 2004). LSA is based on Singular Value Decomposition (SVD) which is a mathematical matrix decomposition technique using factor analysis.

LSA is favored over traditional document analysis techniques and is impacted less by traditional term and word count models (Garcia, 2006). In traditional term count models, repeating terms many times becomes artificially relevant. In turn, long documents are favored because more words bring about higher scores and relevance. Term count models also do not consider relative global frequency of terms across collection of documents. In LSA repetition does not imply relevance because LSA looks at both the local weights and global weights and normalizes them.

LSA is particularly not suited for distinguishing similar terms that vary in context. Synonymy (refers to the characteristic of language to have several terms that mean essentially the same thing) and polysemy (opposite of synonymy; refers to the same term to mean different things in different contexts) makes LSA more difficult (Deerwester et al., 1990). Thus terms that are repeated with different context do not imply a contextual relationship. One approach that can be used to offset this problem is the use of phrase passages and central themes compared to term and word analysis (Grossman et al., 2004).

The study of IE practices can be more quantitative and precise using LSA compared to traditional techniques. Existing techniques are largely subjective and qualitative. Current methods rely on interviews that assume that participants' accounts are a fair reflection of what has actually occurred. Consequently, the use of reports by untrained observers is not an adequate substitute for actual observations. Respondents are also selective in their memory, tend to distort evidence, filter out contradicting details and integrate experiences into their own personal assumptions (Gardner \& Wright, 2009). Subjects also tend to inflate the results due to attribution theory (Gerhart, et al., 1999). Attribution theory is the tendency to make causal explanation about the world based on individual internal beliefs. 
Questionnaires and surveys are also well accepted techniques for conducting research. Unfortunately, research shows that subjects are influenced in their responses by how questionnaires are formatted. Subjects given positive cues about a company will estimate better results than subjects given negative cues about the company. Also, persons with training or experience in the field being studied will have stronger implicit theories regarding the effectiveness of the practices (Gardner \& Wright, 2009).

Another popular technique is the use of informants (Gardner \& Wright, 2009). An informant is a knowledgeable subject or employee inside the company that is used to measure the content and quality of the company's system. Informants pose many problems in the study and are often a source of unreliable data. For example, most informants view the organization from one perspective which means that consistency of practices cannot be uniformly measured across the organization. Because of the time delay of information retrieval informants rely on implicit theories to cue salient information, structure it into coherence and fill the gaps of missing information (Lord, Binning, Rush \& Thomas, 1978). This process ultimately causes information to be biased, unreliable and induces systematic measurement error.

Observing practices is also more difficult and less quantitative compared to LSA techniques. Actions that are observed do not mean that they are desired or expected by anyone, nor that they accomplish the intended functions, nor can they be institutionalized into a social system (Biddle, 1979). For observation techniques to be accurate, analyst need to make observations over a wide variety of persons and range of context. There are also many limitations due to participant observation. Human behaviors are often emitted at a rapid pace that exceeds our ability to note by informal means. Research has shown that behaviors are bundles of complex information (symbols, logic emphasis, warmth, aggressiveness, syntax, humor) and the personal process of filtration suffers from biased conclusions, which means that it is difficult to lead to objective evidence (Biddle, 1979).

An alternative to general observation is the study of organizational documents. LSA may prove an acceptable substitute for traditional research techniques; however, there are noted concerns in this new area of study. First, it is assumed that employees within the organization are aware of IE expectations and can perform them if asked. It is also assumed that these expectations produce a conforming behavior. Also, it is assumed that these expectations have been communicated by management throughout the organization. It is also unknown how management 
sanctions these expectations, which is the positive or negative reinforcement for engaging in the desired behavior. These unknown areas provide many interesting and future opportunities for research.

There are also problems analyzing written expectations. First, we are at the mercy of the biases that may have been introduced by those who originally assembled the records for their own purposes. Additionally, each person shares a unique semantic space in their creation of the expectation that may vary in interpretation. Bedsides these short falls of studying IE corporate documents, inscriptions do represent a continuing existence and a more permanent intention of how IE is being used.

\section{Research methodology}

A document-term(s) matrix was created from numerous Toyota documents; such as the Toyota Way, The Toyota Business Practices, the team member basic training manual, the team member handbook, role of the supervisor, standardized work training manuals, process and system kaizen manual and problem solving for managers. A representation of a document-term(s) matrix is shown in Figure 2. A document-term(s) matrix was created by tabulating the number of term(s) that occur throughout a document. Term(s) count can be identified using a variety of different software programs. A natural characteristic of the document-term(s) matrix is their highly sparse nature which is a high proportion of zeros. This is normal, because very few terms in the collection as a whole are contained in any one document. Other distinguishing characteristics of the matrix are the document vector and the word vector. The document vector is a weighted average of the vectors of words it contains. A word vector is a weighted average of vectors of the documents in which it appears. The document-term(s) matrix was assembled by selecting industrial engineering themes and trends according to previous literature. Table 3 illustrates the text corpus properties of the documents used in the matrix and the themes selected in the study. 


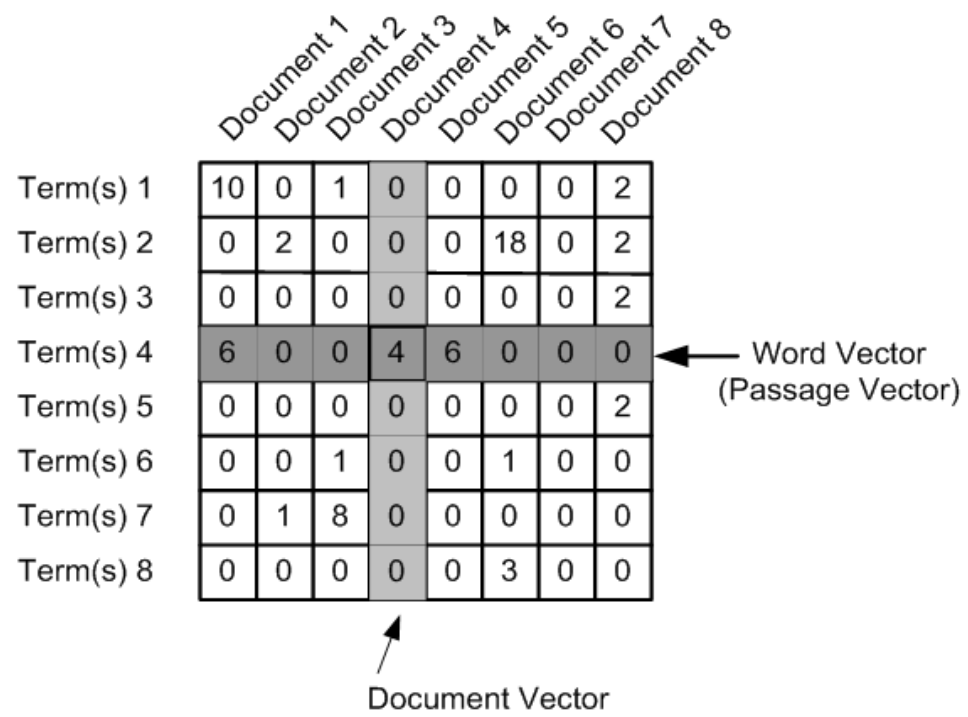

Figure 2. Representation of Document-Term(s) Matrix

\begin{tabular}{|l|l|}
\hline Document Property & Value \\
\hline \# Document Vectors & 20 \\
\hline \# Word Vectors & 8 \\
\hline Total Document Pages & 219 \\
\hline Total Number of Words & 4,108 \\
\hline Avg. Revision Date on Documents & 2006 \\
\hline Latent Semantic Themes & Term(s) \\
\hline \multirow{2}{*}{ Information Gathering } & Direct Observation \\
\cline { 2 - 2 } & Inference by Non-Direct Observation \\
\hline \multirow{2}{*}{ Analyze and examine } & Practical - Scientific Management Techniques \\
\cline { 2 - 2 } & Sophisticated - Modern IE Techniques \\
\hline \multirow{2}{*}{ Outcome-Decision making } & Business Process Re-engineering (BPR) \\
\cline { 2 - 2 } & Standardization \\
\hline \multirow{2}{*}{ Testing and evaluation } & Adaptive one factor at a time (OFAT) \\
\cline { 2 - 2 } & Design of Experiments (DOE) \\
\hline
\end{tabular}

Table 3. Text corpus properties and semantic themes

Next, the Singular Value Decomposition (SVD) algorithm is used to reduce the document-term(s) matrix using equation 1.

$$
\mathrm{A}=\mathrm{USV}^{\top}
$$

Equation 1. SVD Reduction Algorithm

Where $U$ is an $m \times r$ orthogonal matrix whose columns make up the left singular values vectors, $S$ is an $r \times r$ dimensional diagonal matrix whose diagonal elements are termed singular values named " $k$ ", and $V$ is an $r x n$ orthogonal matrix whose columns for the right singular vectors of $A$. $V^{T}$ is the transpose of $V$. Figure 3 gives a schematic representation of $A, U, S$ and $V^{T}$. 


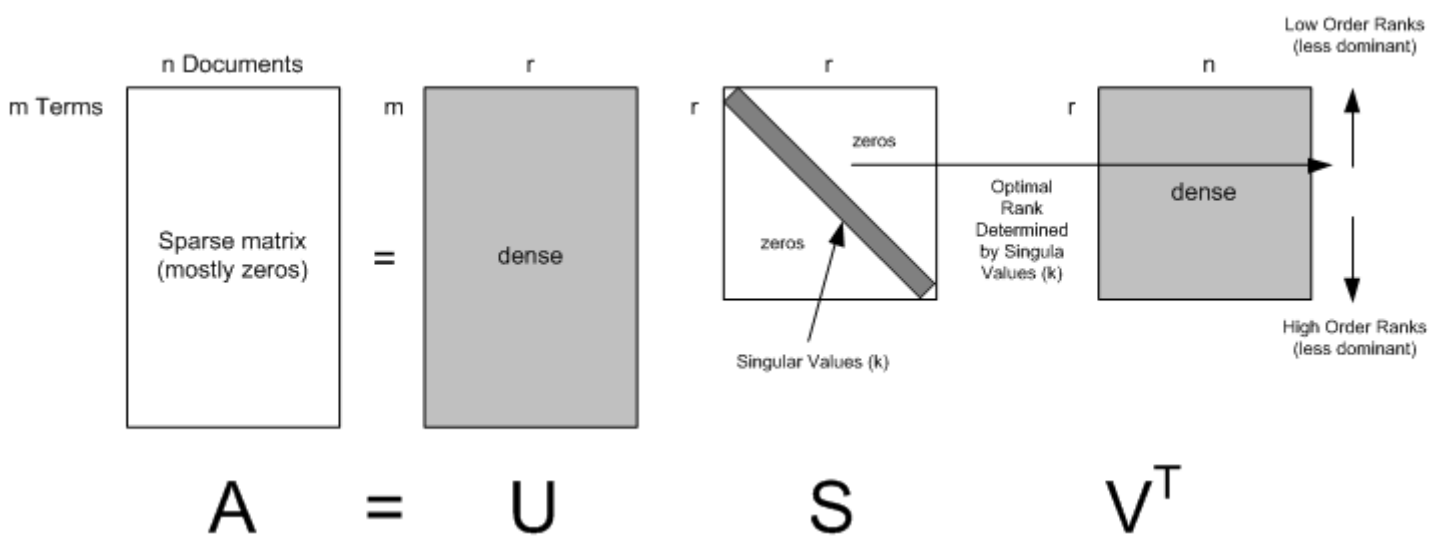

Figure 3. SVD Representation of the document-term(s) matrix

Calculating USV $V^{T}$ consists of finding the eigenvalues and eigenvectors of $A A^{T}$ and $A^{T} A$. The eigenvectors of $A^{T} A$ from the columns of $V$, the eigenvectors of $A A^{T}$ form the columns of $U$. Also, the singular values in $S$ are square roots of eigenvalues from $A A^{T}$ or $A^{T} A$. The singular values are the diagonal entries of the $S$ matrix and are arranged in descending order. The singular values are always real numbers. If the matrix $A$ is a real matrix, then $U$ and $V$ are also real. The last step in LSA is to map the semantic space using the unit vector of each rank of the reduced dimensional space $V^{T}$.

\section{Interpretation of results in latent semantic analysis}

The overall goal in LSA is to map the dominate semantic themes in a reduced dimensional space. The reduced dimensional space represents all word and document vectors in the semantic space or text corpus. Mapping techniques vary and for a more complete description please see the work of Garcia (Garcia, 2006). This work will map the strength (i.e. magnitude) of each word vector and its ranks to illustrate the level of dominance throughout the document collection. Rank 1 (lower order) is the most dominant rank followed by rank 2 and so on. The singular value matrix indicates through a scree plot (not shown) the optimal rank. Ranks beyond the " $k$ " value are less dominant.

Plots shown in Figure 3 to 6 will all approach the maximum rank at a coordinate position 1,1 . Consequently, plots can also be analyzed simultaneously by comparing the distance from the origin to the rank 1 data point. In this way, plots can be analyzed locally (analyzing the decaying nature of each rank within a plot) and globally (by comparing the rank 1 position of each plot). 


\section{Results}

LSA plots are shown in Figures 4 through 7 detailing Toyota's managerial practices from an industrial engineering perspective. These four figures attempt to describe how a manager from Toyota is expected to apply some of the same industrial engineering logic or thinking styles in the workplace. Each figure illustrates a certain industrial engineering activities, namely, how to access, analyze, test and achieve work outcomes.

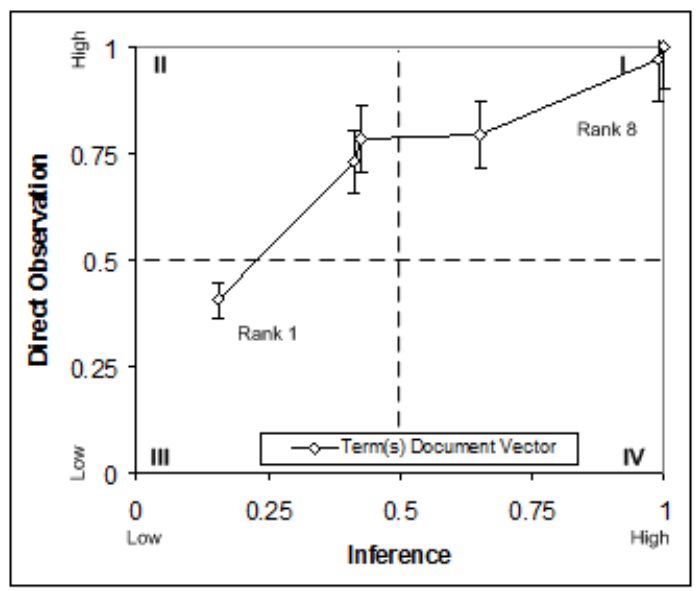

Figure 4. LSA Plot: Toyota's thinking for accessing information

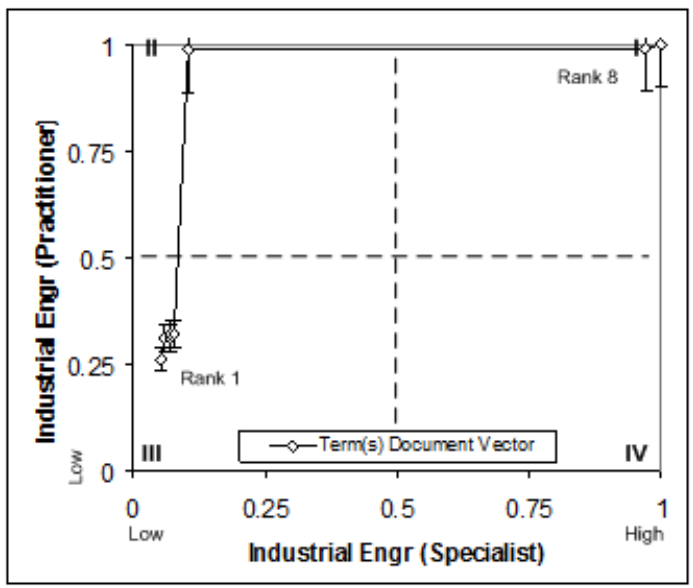

Figure 5. Toyota's thinking for analyzing information 


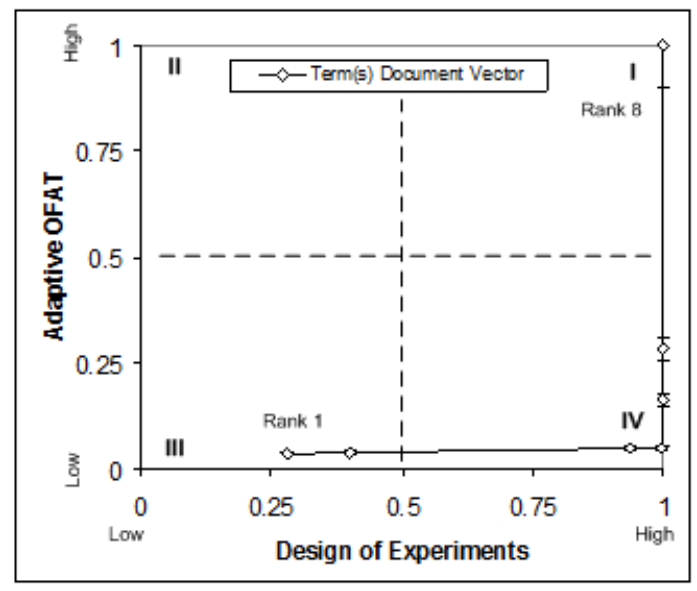

Figure 6. Toyota's thinking for testing information

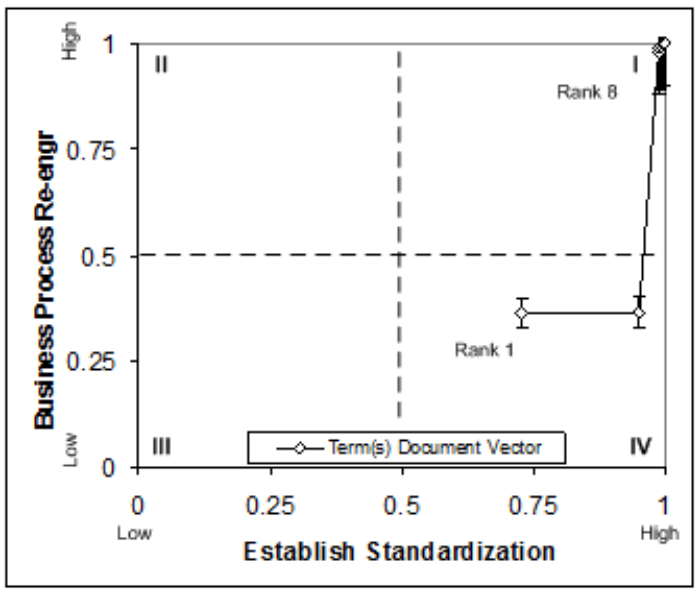

Figure 7. Toyota's thinking for achieving work outcomes

\section{Discussion}

Figure 4 evaluates Toyota's managerial approach for assessing workplace problems. The figure compares the scientific management approach which is based on direct observation and the more modern IE perspective, listed here as inference or nondirect observation. This figure attempts to evaluate how managers at Toyota are trained in assessing the workplace. More specifically, when a manger begins to question or speculate organizational activities or functions, there are two general approaches managers are trained to assess the current situation. A rank 1 data point in quadrant four would indicate that a manager's starting point in the investigation is to gather information by searching through a variety of different sources such as reports, shift logs, e-mails and databases. Data points in quadrant two would mean that a manager's first instinct into inquiring and assessing a workplace issue or problem is to see the problem first hand. Meaning that it is more 
important to judge the situation personally without trying to make assumptions or inferences about actual situation.

Results suggest that Toyota strongly favors the scientific management approach in assessing workplace problems. Figure 4 substantiates quantitatively that Toyota trains it managers in genchi genbutsu which in Japanese means go and see. Managers are expected to go to the source to find facts to make correct decisions. Compared to more modern IE techniques which views that data is important, Toyota believes that more emphasis should be placed on facts. Managers should confirm facts at the shop floor or the source to improve decision making. Toyota does not want its managers to waste time discussing endless possibilities without seeing the problem occur first hand.

This data also implies that management should not rely on other employees' interpretation of the problem. This could be interpreted negatively if employees feel that they cannot work with trust within the company. It would be expected that Toyota is effective at teamwork because employees trust one another. On the contrary, direct observation does not replace discussion instead it provides the starting point for discussion. If managers approve countermeasures and trials through discussion employees will get the impression that decisions should be based on relying on other people's interpretation of the problem. This also means that employees feel less involved and equipped to solve workplace problems within their grasp. Overtime, less emphasis will be paid to seeing problems first hand which also damages employee involvement.

It could also be argued that Toyota's scientific management approach for information gathering is out of date, unpractical and too slow for modern business. Consider a manager who is expected to go and see every problem of the plant. This would mean that managers would have to be nearly everywhere on the shop floor for every disturbance. Consequently, managers already know the problems in their work area and the types of fixes to solve them. It would be hasty for the manager not to rely on various information sources and data streams. Certainly a wide inference on various information channels would allow managers a more wellinformed and balanced decision.

Toyota's concept of genchi genbutsu simply means that direct observation should be applied at the level for the role. Obviously, for a direct labor position genchi genbutsu at that level is more related to a process. For a manager genchi genbutsu is more applicable to system related issue. For a vice president, genchi genbutsu would mean that the VP would visit other plants with similar process or problem in 
the region. It is also important to note that not all disturbances result in a major problem solving activity. For example, on a assembly line with over 350 people Toyota will typically have about 1.200 andon pulls. Not all andons are problem solving or genchi genbutsu visits by a manager. Most andons are answered by a team leader to adjust or correct the process. Yet, when problems do reach a point of escalation or severity, managers at Toyota are expected to see the problem first hand. If the problem solving team did not actually see or witness the problem first hand, the countermeasure trial would not be approved. This is important because data does not replace facts gathered through genchi genbutsu.

Direct observation also allows managers to build consensus with other managers in speeding up decision making. Toyota encourages managers to practice genchi genbutsu together to fully understand the situation. However, this requires managers to observe the situation without preconceptions. If managers do not go to the source with a blank mind their decision making will be biased. Consequently, if managers assume that they know the situation genchi genbutsu will not provide much value mainly because the investigation will not lead to the true point of cause. Therefore, direct observation cannot be applied correctly unless managers have an open mind.

Figure 5 compares the types of industrial engineering techniques to analyze work at Toyota. For example, quadrant four illustrates the use of sophisticated IE tools such as affinity diagrams, matrix data analysis and statistical techniques including analysis of variance, ANOVA and regression analysis (Mizuno, 1988). Quadrant two shows a more practical approach to industrial engineering. Similar to Ishikawa's seven tools of quality, quadrant two considers charting as one of the basic techniques in documenting and analyzing processes relating to products and people (Ishikawa, 1985).

Results suggest that Toyota's preference to industrial engineering techniques heavily favors scientific management practices. This means that Toyota would rather managers apply techniques that can be shared more easily across the organization than to adopt practices that can only be applied by a select group of employees. This data substantiates quantitatively that Toyota does not follow mainstream industrial engineering practices such as six sigma which can only be applied by specialists or master black belts. This is in agreement with most views on Toyota's practices which encourage similar techniques to be used by everyone in the organization. 
This data can also be explained by Toyota's emphasis on their 8-step problem solving process which represents the standardized method for solving workplace problems. Toyota's problem solving technique has been shown to meet the needs of novice problem solvers by encouraging focusing skills early on in the problem solving process. Cognitive skills that encourage narrowing allows novice problem solvers to spend less time searching for relevant information. This is significant because its use is intended for a wider audience compared to six sigma's DMAIC process which is more tailored for expert problem solvers such as master black belts.

Toyota's reliance on basic charting can also be seen by the use of their yamazumi charts and their material and information (M\&I) charting techniques. Yamazumi is Toyota's technique for line balancing which is performed by their team leader role. The team leader is a direct labor position, one level higher than the team member position, and is responsible for completing yamazumi analysis for work balancing every month. Team leaders use this simple charting technique to analyze cycle times to reduce idle and overburden of work stations. The M\&I charting technique is used by management to examine systems (i.e. several processes combined) to reduce lead time. Toyota's yamazumi and M\&I charting techniques are simplified approaches in analyzing work at the appropriate level. This data demonstrates that Toyota is deploying techniques similar to those used during the era of scientific management which are more easily transferred throughout the organization. This means that Toyota is not training its managers to be skilled like a master black belt because those skills cannot be easily applied at a team leader or group leader position.

This raises the question that if management uses a set of IE tools different than the rest of the organization (as in the case of modern IE or six sigma culture) how likely would those charting techniques be taught, supported or recognized? Consequently, how would learning and knowledge sharing be compatible among different work groups and levels if different analysis is used to evaluate workplace conditions? From Toyota's point of view, sharing the same type of thinking or version of industrial engineering is better than being incorrect positionally. That is, establishing a common language to analyze workplace conditions is essential for strengthening the organizations ability to apply teamwork.

Figure 6 shows a comparison between two basic experimentation techniques used to examine and test countermeasures. Quadrant four illustrates one of the most widely used technique in conducting tests, namely experimental design also known 
as the design of experiment (DOE) technique. Data in quadrant four would indicate that the management preference would be to perform a wide range of testing to fully understand the variables and their interdependencies in establishing the most effective countermeasure. Quadrant two exemplifies the adaptive one factor at a time (OFAT) testing methodology which progressively modifies the testing variables each test run. This technique offers one of quickest alternatives in testing to achieve a desired outcome without spending the time to fully understand the contribution of each factor. While OFAT provides a cheaper alternative compared to the more time and resource demanding DOE techniques, it does allow quicker sequential learning when the goal is to achieve a net improvement.

Results imply that Toyota prefers the adaptive OFAT approach compared to the more widely known DOE technique. This data could be explained by Toyota's kaizen philosophy which is based on improvement rather than complete understanding of interacting factors and variables. Meaning, the path to improvement is more important than time spent on optimizing a system. It could be argued that Toyota doesn't see value in learning as most DOE activists would. This would suggest that Toyota is looking for a quick gain rather than the most advantageous countermeasure. Does this say that Toyota is against learning? It would appear that there are lost learning opportunities for not applying a more complete and structured testing method that is employed in the modern IE profession.

The answer can be explained by defining kaizen. From Toyota's perspective kaizen is defined as small and continuous improvement that can add up into big results. The kaizen philosophy is a small risk philosophy, meaning a small step of improvement rather than a large leap. By implementing adaptive OFAT experiments on a small scale it is less necessary to optimize countermeasures. Specifically, if an organization views kaizen as a radical and dramatic approach to improvement it would make sense to more fully understand all of the variables involved. This is illustrated in Toyota's 8-step problem solving methodology. Toyota's algorithm for solving problems is extremely efficient at breaking down large problems into small problems. This means that when countermeasures are tested, the scale and scope of the problem has already been reduced. This allows countermeasures to be verified easier and quicker. If Toyota did not break down the problem, a DOE would be required, since several countermeasures would have to be applied simultaneously because several root causes are being analyzed. It is argued that Toyota's use of the adaptive OFAT approach combined with their 8-step problem solving methodology allows movement towards improvement quicker than an exhaustive experimental design. 
Figure 7 compares two industrial engineering outcomes when deciding the best course of action for improvement. Quadrant two represents one of the most recognized techniques used in scientific management, namely standardization. Standardization is the quickest and most efficient approaches for eliminating and reducing waste in the workplace. Interestingly, most modern IE techniques do not emphasize standardization. In most cases, modern IE handbooks do not consider standardization as a chapter while earlier (1970s and prior) text would. Quadrant two illustrates one of the most widely popularized IE techniques for improvement, that is, business process redesign or re-engineering (BPR). BPR as described earlier is a huge departure from standardization. BPR proponents view that studying and stabilizing existing systems through study is largely a waste of time; being that the existing system is so inefficient it is better to start from scratch.

Results suggest that Toyota rarely views that any system should be overhauled, replaced or re-designed. Instead, Figure 7 implies that Toyota encourages an older version of IE, namely standardization. These results highlight that standardization is more significant than overtaking existing systems. This means that managers are constantly encouraging employees to look for ways to stabilize existing systems rather than to change them. This data is in agreement with most Japanese views on conservatism, yet most lean practitioners are eager to rush to kaizen or drastically modify their systems.

These results contradict that TPS is another technology aimed at BPR. Meaning, most lean practitioners have the belief that Toyota utilizes a current state and a future state in deciding improvement outcomes. This is false. Toyota doesn't use future state maps. They do not exist. If they did, it would mean that Toyota's 8step problem solving process would have to be violated. In other words, jumping to a countermeasure (i.e. future state) without performing Step 1, Step 2, Step 3 and Step 4 would be illegal. Toyota doesn't develop a countermeasure until Step 5. However, future state mapping like BPR concepts are appealing because it means the existing system doesn't have to be studied. It takes allot of work to identify problems and corrections to an existing system. It is far more enjoyable, sexy and fashionable to start with a clean slate, making it much easier to sell and market. Again, like the Gilbreth's pointed out some 50 years ago, many charlatans got into time and motion study without understanding the purpose of scientific management. Like lean, most practitioners place value in obtaining speedy results rather than achieving consistency, predictability and stability. Toyota views that stability (i.e. standardization) is the prerequisite for kaizen. Meaning that jumping from one unstable state to another one does not guarantee defect free products or 
processes. Toyota's preference on standardization compared to BPR demonstrates quantitatively that managers follow an older view of the IE profession.

\section{Conclusion}

This work uses a new method for analyzing managerial practices. LSA was used to mathematically describe Toyota's approach towards industrial engineering. Various components and features of Toyota's management techniques were identified and described in a way that offers many unique insights. This technique has many other potential uses and can be accomplished with minimum resources in evaluating an organizations ideal strategy, image or management technique with less bias.

The other goal in this work was to understand the similarities or differences of industrial engineering towards Toyota's management style. Early work indicates that Ohno and Shingo modeled much of their thinking towards the earlier versions of industrial engineering, namely scientific management. Up to this point, most work describes Toyota or lean methods as modern IE techniques. This research shows quantitatively that Toyota's managerial practices of today very much resemble the IE profession in the early 1900s. It is argued that Toyota has remained successful applying TPS because they have sheltered themselves from modern IE influences that seek to raise the competence of a single employee (i.e. industrial engineer) rather than the basic thinking skills of all employees. The findings of this work suggest that Toyota's managerial practices would rather deploy simplified techniques that are easy to learn by all rather than to leave kaizen up to a single group (i.e. continuous improvement team) or an individual (i.e. kaizen specialist and master black belt).

These findings could suggest the following. True kaizen means small improvements add up to big results, which means the organization needs many ways to involve lots of people. The involvement techniques have to be practical, easy to apply and quick to implement. In this context, it makes sense why Toyota is pushing for skills such as direct observation, charting, standardization, and how to run simple test to verify solutions. Surprisingly, modern IE approaches (at least from studying IE handbooks) do not emphasize teamwork, doing practical things first, or using techniques that relate to everyone. It could be argued that Toyota is watering down IE thinking and should give up on the idea of trying to treat everyone as an engineer. Consider an organization that does not have a progressive human resource function. For some companies a small group of kaizen specialists or master black belts may be an optimal solution compared to fixing hiring processes 
and workplace incentives to learn. While not a competitive advantage, the modern IE approach could raise an organizations performance.

Lastly, this work illustrates that Toyota has been successful passing down scientific management practices from generation to generation. Results show that Toyota is not following mainstream practices but instead trying to maintain basic fundamentals and common sense work practices. Interestingly, Toyota's drive to "get back to basics" continues and remains a constant force among managers to prepare future generations of Toyota employees.

\section{Acknowledgments}

We are especially grateful to the Journal of Industrial Engineering and Management journal reviewers for their insights and comments which overall improved the quality of this paper. Subsequently this article benefited from the comments of Dr. Arlie Hall, Ken Kreafle, and Rich Alloo. This work could also not be completed without TEMA and their continued support in the University of Kentucky Lean Systems program.

\section{References}

Anderson, A. (1928). Industrial Engineering and Factory Management. New York: The Ronald Press Company.

Anderson, V., \& McLean, R. (1974). Design of Experiments: A realistic approach. New York: Dekker.

Askin, R., \& Goldberg, J. (2002). Design and analysis of lean production systems. New York: John Wiley and Sons, Inc.

Bicheno, J. (2000). The Lean Toolbox. Buckingham, England: PICSIE Books.

Biddle, B.J. (1979). Role theory: Expectancies, identities, and behaviors. New York: Academic Press.

Bowker, A., \& Lieberman, G. (1971). Industrial Statistics in Handbook of Industrial Engineering and Management. Ed Ireson \& Grant.

Castro, M., Sebastian, R., \& Quesada, J. (2010). A systems theory perspective of electronics in engineering education. IEEE EDUCON Education Engineering, The Future of Global Learning Engineering Education, Madrid, Spain, 14-16 April. 
Cho, F. (2001). The Toyota Way. Toyota Institute, Toyota Motor Corporation (unpublished).

Cho, F. (2005). Toyota Business Practice. Toyota Institute, Toyota Motor Corporation (unpublished).

Cooke, M. (1910). Academic and Industrial Efficiency. Bulletin of the Carnegie Foundation for the Advancement of Teaching, 5, 6 .

Czitrom, V. (1999). One-Factor-at-a-Time Versus Designed Experiments. The American Statistician, May, 53(2).

Daniel, C. (1973). One at a time plans. Journal of the American statistical association, 68, 353-360. http://dx.doi.org/10.2307/2284076

Deerwester, S., Dumais, S.T., Furnas, G.W., Landauer, T.K., \& Harshman R.A. (1990). Indexing by latent semantic analysis. Journal of the Society for Information Science, 41(6), 391-407. http://dx.doi.org/10.1002/(SICI)10974571(199009)41:6<391::AID-ASI1>3.0.CO;2-9

Dennis, P. (2007). Lean Production Simplified ( $2^{\text {nd }}$ ed.). CRC Press.

Friedman, M., \& Savage, L. (1947). Planning experiments seeking maxima, in Techniques of statistical analyses. New York: Eisenhart, C., Hastay, M., \& Wallis, W., McGraw-Hill, 365-372.

Garcia, E. (2006). SVD and LSI Tutorial 4: Latent Semantic Indexing (LSU) How-to Calculations, www.miislita.com.

Gardner, T., \& Wright, P. (2009). Implicit human resource management theory: A potential threat to the internal validity of human resource practice measures. The International Journal of Human Resource Management, 20(1), 57-74. http://dx.doi.org/10.1080/09585190802528375

General Accounting Office (GAO) (1995). Business process reengineering assessment guide. Washington, DC: GAO.

Gerhart, B., Wright, P., \& McMahan, G. (1999). Measurement error in research on the human resources and firm performance relationship: Further evidence and analysis. Personnel Psychology, 53(4), 855-872. http://dx.doi.org/10.1111/j.17446570.2000.tb02420.x 
Gilbreth, F. (1973). Primer of scientific management. New York: Easton Hive Publishing Company.

Going, C. (1911). Principles of industrial engineering. London: Hill Publishing Co., Ltd, McGraw-Hill Book Company, Inc.

Gottlieb, B. (1971). The Attitudes of organized labor toward industrial-engineering methods, in Ireson \& Grant, 1971.

Grossman, D., \& Frieder, O. (2004). Information retrieval: Algorithms and heuristics. Springer Publishing.

Harrington, E. (1911). The twelve principles of efficiency. New York: The Engineering Magazine.

Ireson, W., \& Grant, E. (1971). Handbook of industrial engineering and management ( $2^{\text {nd }}$ Ed.). New Jersey, Englewood Cliffs: Prentice-Hall Inc.

Ishikawa, K. (1985). What is total quality control? The Japanese way. Englewood Cliffs, New Jersey: Prentice-Hall.

Jackson, T. (2006). Hoshin Kanri for the lean enterprise. New York: Productivity Press.

Jugulum, R., \& Samuel, P. (2008). Design for Lean six sigma: A holistic approach to design and innovation. New Jersey, Hoboken: John Wiley \& Sons, Inc.

Kadota, T. (1982). Charting techniques, in Handbook of industrial engineering. New York: Salvendy, G., John Wiley \& Sons, Inc.

Katzell, R., Bienstock, P., \& Faerstein, P. (1977). A guide to worker productivity experiments in the United States, 1971-1975. New York: New York University Press.

Landauer, T. (1998). Learning and representing verbal meaning: The latent semantic analysis theory. American Psychology Society, 7(5).

Landauer, T. (2004). From paragraph to graph: Latent semantic analysis for information visualization. Colloquium of the National Academy of Sciences, April 6, 2004, 101(1).

Lee, C. (1996). Process reengineering at GTE: Milestones on Journey Not Yet Completed. Strategy and Business, 5. 
Lee, R., \& Dale, B. (1998). Business process management: A review and evaluations. Business Process Management Journal, 4(3), 214-225. http://dx.doi.org/10.1108/14637159810224322

Liker, J., \& Hoseus, M. (2008). Toyota Culture - The Heart and Soul of the Toyota Way. McGraw-Hill.

Lo, V.H.I., \& Sculli, D. (1995). Industrial engineering and TQM. Training for quality, 3(3), 4-7. http://dx.doi.org/10.1108/09684879510093335

Lord R.G., Binning, J.F., Rush M.C., \& Thomas J.C. (1978). The effect of performance cues and leader behavior on questionnaire ratings of leadership behavior. Organizational Behavior and Human Performance, 21(1), 27-39. http://dx.doi.org/10.1016/0030-5073(78)90036-3

Ludwig von Bertalanffy, K. (1968). General System Theory: Foundations, Development, Applications. New York: George Braziller.

Manganelli, R., \& Klein, M. (1994). The reengineering handbook: A step by step guide to business Transformation. New York: AMACOM.

Mar, B. (1994). Systems engineering basics. Journal of NCOSE, 1(1), 17-28.

Martens, H., \& Allen, D. (1969). Introduction to systems theory. Columbus, Ohio: Charles E. Merrill Publishing Co.

Martin, K., \& Osterling, M. (2007). The kaizen event planner: Achieving rapid improvement in office, service and technical environments. New York: Productivity Press.

Mika, G. (2006). Kaizen: Event implementation manual ( $5^{\text {th }}$ Ed.). Dearborn, MI: Society of Manufacturing Engineers.

Mizuno, S. (1988). Management for quality improvement. Cambridge, MA: Productivity Press.

Mogensen, A. (1935). How to set up a program for motion economy. Factory Management and Maintenance Plant Operation Library, 93(11).

Mogensen, A. (1935b). From 59 steps to 22. Factory Management and Maintenance, 93(3), 17-17. 
Montgomery, D. (2005). Design and Analysis of Experiments. John Wiley \& Sons, Inc.

Ohno, T. (1988). Toyota Production System: Beyond Large-Scale Production. New York: Productivity Press.

Ohno, T. (1988b). Workplace Management. Productivity Press.

Pyzdek, T., \& Keller, P. (2009). The Six Sigma Handbook, (3 ${ }^{\text {rd }}$ Ed.). New York, NY: McGraw-Hill.

Rayfield, J. (1964). Training a standards engineer. Standards Engineering, 14(11), 1-8.

Salvendy, G. (2001). Handbook of Industrial Engineering: Technology and Operations Management. New York: John Wiley and Sons, Inc. http://dx.doi.org/10.1002/9780470172339

Saunders, B. (1982). The Industrial Engineering Profession, in Handbook of Industrial Engineering. New York: John Wiley and Sons, Inc.

Shingo, S. (2005). A study of the Toyota Production System: From an Industrial Engineering Viewpoint. New York: CRC Press, Taylor Francis Group.

Srinivasan, M. (2004). Streamlined: 14 Principles for Building and Managing the Lean Supply Chain. USA: Thomson.

Staley, J., \& Delloff, I. (1963). Improving Individual Productivity. US: The American Management Association, Inc.

Tanco, M., Ilzarbe, L., \& Alvarez, M. (2009). Barriers faced by engineers when applying design of experiments. The TQM Journal, 21(6), 565-575. http://dx.doi.org/10.1108/17542730910995846

Tapping, D. (2007). The Lean Pocket Book Handbook for Kaizen Events. USA: MCS Media, Inc.

Taylor, F. (1911). Principles of Scientific Management. New York and London: Harper \& brothers.

Taylor, J., Dargan, T., \& Wang, B. (2001). Process Design and Reengineering, in Handbook of Industrial Engineering ( $3^{\text {rd }}$ Ed.). New York: John Wiley \& Sons. http://dx.doi.org/10.1002/9780470172339.ch62 
Tippett, L. (1953). The ratio delay technique. Time and motion study, 2(5), 10-19.

Warfield, J., \& Cardenas, A. (1994). A Handbook of Interactive Management (2 ${ }^{\text {nd }}$ Ed.). Iowa State Press.

Wedgwood, I. (2007). Lean Sigma: A Practitioners Guide. Boston MA: Prentice Hall.

Zandin, K. (2001). Maynard's Industrial Engineering Handbook (5 ${ }^{\text {th }}$ Ed.). USA: McGraw-Hill.

Journal of Industrial Engineering and Management, 2011 (www.jiem.org)

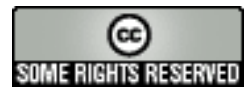

Article's contents are provided on a Attribution-Non Commercial 3.0 Creative commons license. Readers are allowed to copy, distribute and communicate article's contents, provided the author's and Journal of Industrial Engineering and Management's names are included. It must not be used for commercial purposes. To see the complete license contents, please visit http://creativecommons.org/licenses/by-nc/3.0/ 